Proceedings

\title{
Improvement of methane yield using bioaugmentation technique in a thermophilic anaerobic digestion process
}

\author{
Aixa Kari Gállego-Bravo¹, Jaime García-Mena², Alberto Piña-Escobedo², Gloria López-Jiménez³, \\ María Eugenia Gutiérrez-Castillo" and Luis Raúl Tovar-Gálvez ${ }^{4, *}$ \\ 1 Instituto Politécnico Nacional, Centro Mexicano para la Producción más Limpia, Av. Acueducto s/n, 07340 \\ Ciudad de México, México; karigllego@gmail.com \\ 2 Departamento de Genética y Biología Molecular, Cinvestav Unidad Zacatenco. Av. Instituto Politécnico \\ Nacional 2508, Col. San Pedro Zacatenco, CDMX Código Postal 07360. Ciudad de México; \\ jgmena@cinvestav.mx (J.G-M.); apinae@cinvestav.mx (A.P-E.) \\ 3 Instituto Politécnico Nacional, Unidad Profesional Interdisciplinaria de Biotecnología, Departamento de \\ Ciencias Básicas, Av. Acueducto s/n, 07340, Ciudad de México, México; glorialopez@yahoo.com \\ 4 Instituto Politécnico Nacional, Centro Interdisciplinario de Investigaciones y Estudios sobre Medio \\ Ambiente y Desarrollo, Calle 30 de junio de 1520 s/n, 07340 Ciudad de México, México; \\ mgutierrezc@ipn.mx \\ * Correspondence: 1 tovarg@ipn.mx; Tel.: +52-5729-6000 (ext. 52716) \\ + Presented at the $1^{\text {st }}$ International Electronic Conference on Microbiology, 02-30 November 2020; Available \\ online: https://ecm2020.sciforum.net/
}

Published: 02 November 2020

\begin{abstract}
A methanogenic consortium was used to improve the methane yield of a thermophilic anaerobic digestion process of organic fraction of municipal solid waste. The consortium was added to the system in different volume/volume proportions. The results showed that two treatments increased the methane yields by $5 \%$ in comparison to the control. About the bacterial communities, it was identified that the consortium was mainly constituted by members of the phylum Synergistetes. In all the treatments the phyla Firmicutes, Thermotogae, and Synergistetes were dominant and as the proportion of the consortium in the treatments increased, the presence of the family Thermotogaceae also did.
\end{abstract}

Keywords: bioaugmentation; hydrogenotrophic methanogens; organic fraction of municipal solid waste; thermophilic anaerobic digestion

\section{Introduction}

Anaerobic digestion (AD) is a sustainable process for organic waste treatment, as it converts organic matter into energy (in the form of biogas) and digestate. AD is used to degrade various types of organic waste, including lignocellulosic biomass, food waste, agro-industrial waste, animal manure and sludge from wastewater treatment plants [1,2]. However, AD frequently suffers from process instability due to high levels of toxic inorganic substances, variations in operating parameters, as well as imbalance between microbial groups [3]. Bioaugmentation can serve as a mechanism to regain the efficiency of systems due to greater microbial diversity and abundance. This technique is defined as the addition of specific microbial cultures to perform a definite task in a given environment $[4,5]$. In this work, hydrogenotrophic methanogens were used to improve the methane yield of a thermophilic AD process of the organic fraction of municipal solid wastes (OFMSW) in Mexico City.

\section{Materials and Methods}


The OFMSW (substrate) and leachate (inoculum) were collected from a composting plant in Mexico City. The consortium containing the methanogens was isolated from the leachate using basal media. Biochemical methane potential (BMP) test was performed to determine if the consortium influenced the methane yield. A 1:1 volatile solids (VS) ratio substrate/inoculum was operated in 125 $\mathrm{mL}$ serum bottles with a working volume of $60 \mathrm{ml}$. The consortium was added at different volume ratios $(0 \%, 10 \%, 25 \% 50 \%$ and $75 \%)$. The process lasted 32 days at $55^{\circ} \mathrm{C}$ and $60 \mathrm{rpm}$. Every 3 days, biogas composition and generation were determined, through gas chromatography with thermal conductivity detector (TCD) and water displacement, respectively. The identification of the microbial communities of all treatment groups and consortium were done by high throughput DNA sequencing of bacterial and archaeal $16 \mathrm{~S}$ rDNA libraries, samples were taken at day 0,17 and 32.

\section{Results and discussion}

The cumulative methane yields obtained are shown in Figure 1. The $25 \%$ and $50 \%$ treatments got the maximum methane yields in comparison with the control (on average $5 \%$ increase). However, it was also noticeable that only the $50 \%$ treatment had its methane generation peak at a higher rate than the rest of the groups, therefore, it is suspected that the addition of the consortium at that proportion contributed to shorten the adaptation phase of the microorganisms during anaerobic degradation [6]. Regarding the bacterial communities, the phyla Firmicutes, Synergistetes and Thermotogae predominated throughout the process in all treatments (Figure 2). However, in the 50\% and $75 \%$ treatments, the abundance of Synergistetes and Thermotogae dominating as the days went by. Members of the phylum Firmicutes are known to have capacities for the decomposition of organic substrate and fermentation, while the members of Synergistetes can produce a range of organic acids or produce metabolites that are used directly by the methanogens $[2,7]$.

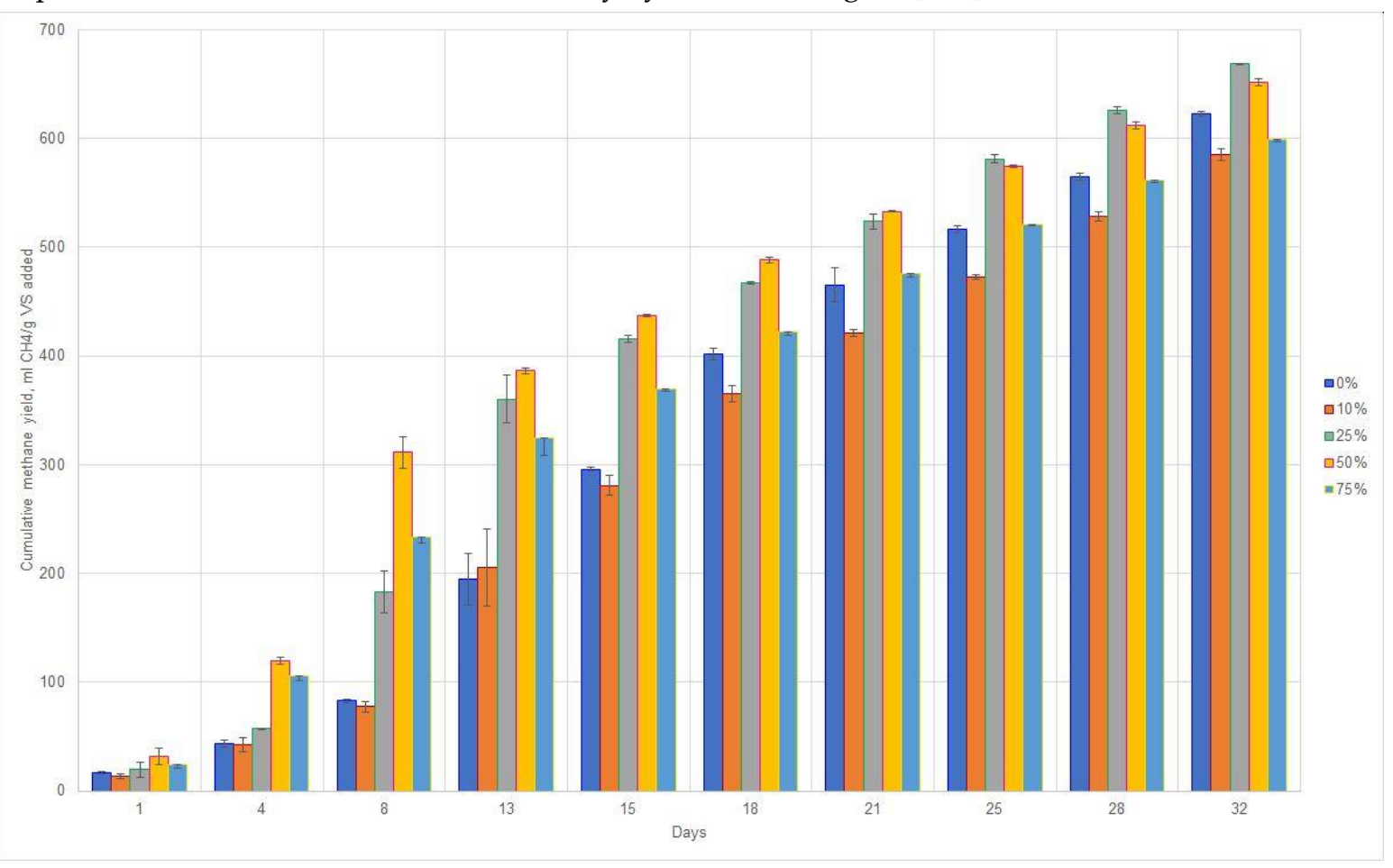

Figure 1. Cumulative methane yields for all treatments. 


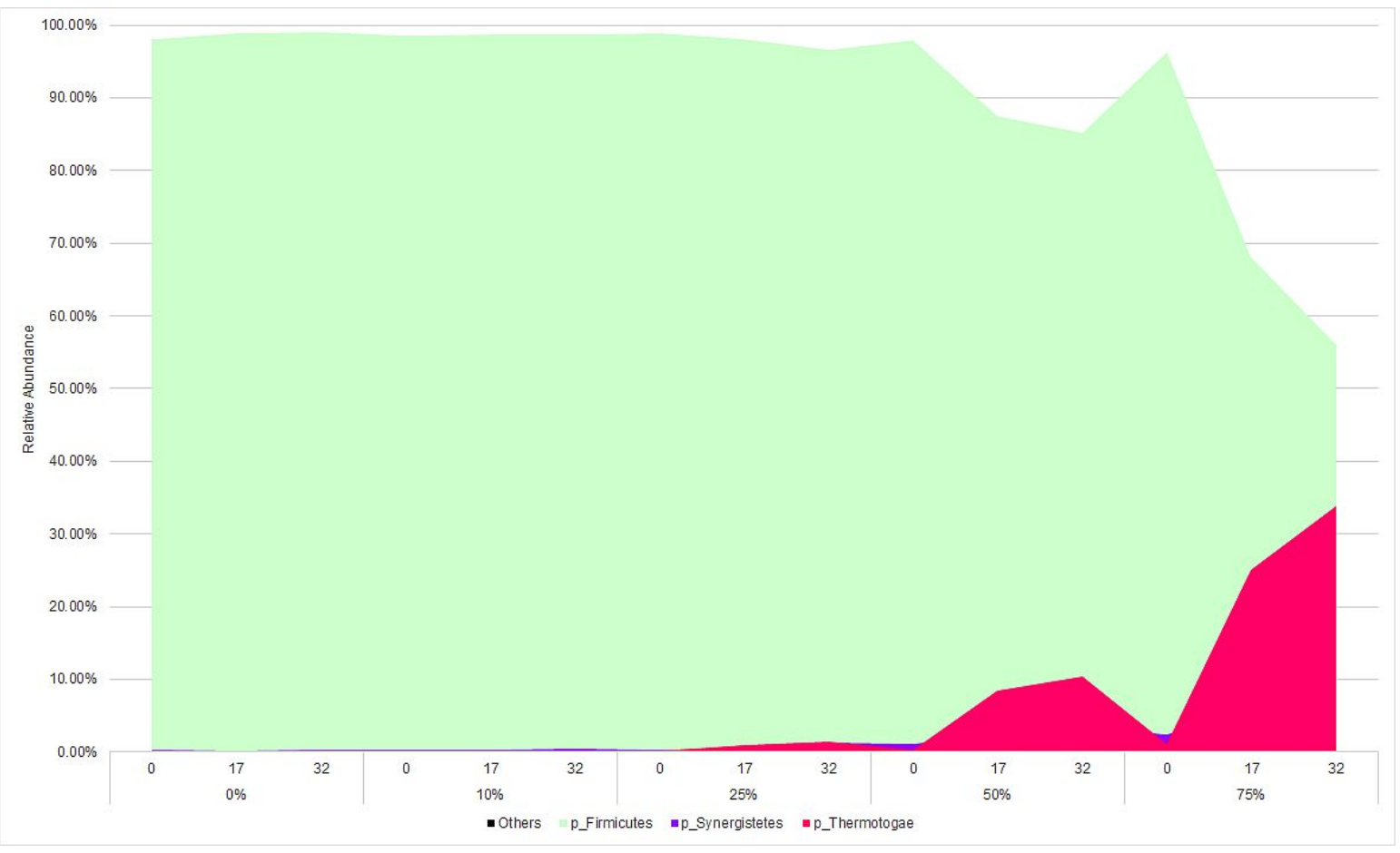

Figure 2. Bacterial relative abundance of all treatments.

\section{Conclusion}

The addition of the methanogenic consortium up to $50 \%$ increased the methane yield of the AD process by around $5 \%$ in comparison to the control. The bacteria found in the system are characterized by being substrate degraders, however the role of the methanogens remains to be determined.

Author Contributions: Conceptualization, AKGB, JGM, GLJ, MEGC and LRTG; methodology, AKGB, JGM, GLJ, MEGC and LRTG; software, APE, JGM; validation, AKGB, JGM, GLJ, MEGC and LRTG; formal analysis, AKGB, JGM, GLJ, MEGC and LRTG; investigation, AKGB, JGM, GLJ, MEGC and LRTG; resources, JGM, GLJ, MEGC and LRTG; data curation, AKGB, JGM, GLJ, MEGC and LRTG; writing-original draft preparation, AKGB, JGM, and LRTG; writing - review and editing, AKGB, JGM, GLJ, MEGC and LRTG; visualization, AKGB; supervision, JGM and LRTG; project administration, LRTG.; funding acquisition, JGM and LRTG.

Funding: This research was funded by CIIEMAD IPN SIP 20172277, 20180942, 20195607 to LRTG, and CONACyT-163235 INFR-2011-01 to JGM. AKGB was granted a CONACyT-700337 doctorate scholarship.

Acknowledgments: We thank Rodrigo García-Gutiérrez for technical support. Samara Anaid Garduño Martínez and Aydée Daniela Reséndiz Ramírez for experimental assistance. Claudia Rodríguez Tapia and Viridiana Rosas Ocegueda for administrative support.

Conflicts of Interest: The authors declare no conflict of interest.

\section{References}

1. Campuzano, R.; González-Martínez, S. Characteristics of the organic fraction of municipal solid waste and methane production: A review. Waste Manag. 2016, 54, 3-12, doi:10.1016/j.wasman.2016.05.016.

2. Lin, L.; Xu, F.; Ge, X.; Li, Y. Improving the sustainability of organic waste management practices in the food-energy-water nexus: A comparative review of anaerobic digestion and composting. Renew. Sustain. Energy Rev. 2018, 89, 151-167, doi:10.1016/j.rser.2018.03.025.

3. Strang, O.; Ács, N.; Wirth, R.; Maróti, G.; Bagi, Z.; Rákhely, G.; Kovács, K.L. Bioaugmentation of the thermophilic anaerobic biodegradation of cellulose and corn stover. Anaerobe 2017, 46, 104-113, doi:10.1016/j.anaerobe.2017.05.014. 
4. Fotidis, I.A.; Wang, H.; Fiedel, N.R.; Luo, G.; Karakashev, D.B.; Angelidaki, I. Bioaugmentation as a Solution To Increase Methane Production from an Ammonia-Rich Substrate. Environ. Sci. Technol. 2014, 48, 7669-7676, doi:10.1021/es5017075.

5. Lebiocka, M.; Montusiewicz, A.; Cydzik-Kwiatkowska, A. Effect of Bioaugmentation on Biogas Yields and Kinetics in Anaerobic Digestion of Sewage Sludge. Int. J. Environ. Res. Public Health 2018, 15, 1717, doi:10.3390/ijerph15081717.

6. Akyol, Ç.; Ince, O.; Bozan, M.; Ozbayram, E.G.; Ince, B. Fungal bioaugmentation of anaerobic digesters fed with lignocellulosic biomass: What to expect from anaerobic fungus Orpinomyces sp. Bioresour. Technol. 2019, 277, 1-10, doi:10.1016/j.biortech.2019.01.024.

7. Ferguson, R.M.W.; Coulon, F.; Villa, R. Understanding microbial ecology can help improve biogas production in AD. Sci. Total Environ. 2018, 642, 754-763, doi:10.1016/j.scitotenv.2018.06.007.

Publisher's Note: MDPI stays neutral with regard to jurisdictional claims in published maps and institutional affiliations.

(C) 2020 by the authors. Submitted for possible open access publication under the terms and conditions of the Creative Commons Attribution (CC BY) license (http://creativecommons.org/licenses/by/4.0/). 